\title{
LIBROS DE POESÍA EN BIBLIOTECAS DEL SIGLO DE ORO (1600-1650)*
}

\author{
José MARÍA DÍEZ BORQUE \\ Universidad Complutense de Madrid
}

\section{INTRODUCCIÓN Y EXPLICACIÓN}

El título de este estudio incita ya una serie de preguntas para las que me hubiera gustado que pudiera haber respuestas satisfactorias. Aun contando con que la poesía tenía unas peculiaridades de creación y de difusión, frente a otros géneros —a ello me refiero más adelante—, se plantean interrogantes semejantes a los que ya señalé en su día para la novela o el teatro ${ }^{1}$ : ¿quiénes y cuántos leían poesía en el Siglo de Oro y qué poesía leían? ¿Cuál era la permanencia de autores, títulos y géneros? ¿Cuáles eran las lecturas predominantes, y las proporciones de la literatura, y de la poesía en particular, en el conjunto? ¿Cómo condicionaba la clase social, el sexo, el precio, la censura, el ámbito ur-

* Este estudio se enmarca en el proyecto I+D: De la biblioteca particular al canon literario en los Siglos de Oro (FFI 2009-07862), del que soy IP.

1 José María Díez Borque, «Bibliotecas y novela en el Siglo de Oro», Hispanic Review, LXXV, 2, 2007, págs. 181-203; José María Díez Borque, «Novelas en bibliotecas particulares del Siglo de Oro (1600-1650) (III): Picaresca», Estudos para I. Resina, M. L. Pires, M. Vitalina Leal, ed. I. Almeida, M. J. Rocheta, T. Amado, Lisboa, Universidad, 2007, págs. 537-567; José María Díez Borque, «Novelas en bibliotecas particulares del Siglo de Oro (1600-1650) (II): Pastoril», Arkadien in den Romanischen Literatures. Zu Ehren von Sebastian Neumeister, ed. R. Friedlein, E Poppenberg, A. Volmer, Heidelberg, Universidad, 2008, págs. 189-213; José María Díez Borque, «Novelas en bibliotecas particulares del Siglo de Oro (I): Picaresca», Homenaje a G. Caravaggi (en prensa); José María Díez Borque, «Libros de teatro en bibliotecas particulares del Siglo de Oro», En buena compañía: estudios en honor de Luciano García Lorenzo, ed. J. Álvarez Barrientos, Ó. Cornago, A. Madroñal, C. Menéndez Onrubia, Madrid, CSIC, 2009, págs. 225-236. José M. ${ }^{a}$ Díez Borque, «Libros de teatro en bibliotecas de clases trabajadoras (1600-1650)», El sabio y el ocio. Zu Gelehrsamkeit und Muße in der spanischen Literatur und Kultur des Siglo de Oro. Festschrift für Christoph Strosetzki zum 60, Geburtstag, Tübingen, Gunter Narr, 2009, págs. 119-133; José M. ${ }^{a}$ Díez Borque, «Ocios de la nobleza: libros de teatro en sus bibliotecas (16001650)», De Cervantes a Calderón: Estudios sobre la literatura y el teatro español del Siglo de Oro. Homenaje al Profesor Kazimierz Sabik, ed. Karolina Kumor, Instituto de Estudios Ibéricos e Iberoamericanos, Universidad de Varsovia, Varsovia, 2009, págs. 325-338; José M. ${ }^{a}$ Díez Borque, Literatura (novela, poesía, teatro) en bibliotecas particulares del Siglo de Oro español (1600-1650), Madrid, Iberoamericana (en prensa). Hay coincidencias y partes comunes en estos estudios en lo que es pertinente. 
bano o rural? Además la poesía, en particular, obliga a plantearse, como decía, las relaciones, proporciones y funciones de oralidad-manuscrito-impreso, contando no sólo con el libro, sino con el océano de pliegos de cordel y otro tipo de impresos. En todo caso estas preguntas, y muchas más, como diré después, llevan a la obligación de acercarse a la «realidad de verdad», como decía Torres Naharro, para analizar y valorar las coincidencias y diferencias construidas por la historia de la literatura, la memoria literaria del pasado, y la realidad, día a día, de la poesía en su siglo. Se va avanzando en alguno de estos aspectos ${ }^{2}$, pero queda mucho camino por recorrer.

Mi intención en lo que sigue es mucho más limitada que dar respuesta a tantas interrogaciones, desentendiéndome de aspectos concretos de lectura, siempre terreno conjetural, problemático y resbaladizo, aunque se va avanzando en ello ${ }^{3}$, pero alguna contribución haré aquí.

He estudiado 65 inventarios publicados de bibliotecas particulares del Siglo de Oro en el período de 1600 a 1650, de distintas clases sociales y áreas geográficas, partiendo de la información que proporcionan al respecto Chevalier, Lasperas, Dadson, Prieto, Bouza, Manso... ${ }^{4}$. No se me oculta la existencia de

\footnotetext{
${ }^{2}$ No puedo entrar aquí en la rica y extensa bibliografía sobre bibliotecas, porque desborda los límites y alcance de este estudio, pero quiero recordar, aunque sea en mera nómina, los trabajos, en distintos aspectos, de varios investigadores, que se suman a otros que citaré. Desde los de amplio alcance, cuestiones generales, historia, función, tipología, organización, escritura-lectura, etc., de Amado, Baratín, Bouza, Cátedra, Chartier, Escolar, Geal, Hernández González, Huarte, López (M), López Vidriero, Martínez Pereira, Millares, Solís..., a los de bibliotecas particulares: Dadson (varias), Entrambasaguas (Ramírez de Prado), Freitas (Marqués de Niza), Prieto (palacio de Pastrana)..; Barbier, Bouza, Chartier... (realeza, príncipe). Habría que sumar estudios sobre bibliotecas del clero de varios estudiosos: Burgos, Hevia, Vaquerizo; de mujeres: Cátedra, GuillaumeAlonso...; distintas áreas geográficas y ciudades: García Cárcel (Cataluña); Prieto (Madrid); Rojo (Valladolid); Sanz (Sevilla); Weruaga (Salamanca); etc.

${ }^{3}$ Varios de los estudios citados en notas anteriores, al tratar de las bibliotecas, se ocupan, también, de la lectura y su variada problemática. Como queda dicho, no entro aquí en estas cuestiones, pero no quiero dejar de citar, de nuevo en mera nómina, a varios investigadores que han hecho aportaciones en este campo, y a cuyos estudios puede acudir el lector interesado. Sumaré a los ya citados: Baranda, Bödeker, Capello, Carvallo, Castillo, Cayuela, Cerdá, Courcelles-Val Julián, Darnton, Frenk, Geal, Goulemot, Herpel, Ife, Jauralde, Le Flem, López, F., Luengo, Manguel, Peña, Petrucci, Prieto, Rey, Rojo, Salavert, Sanz Hermida, Simón, Texton... Por otra parte, de gran interés son algunos colectivos como Livre et lecture en Espagne et en France sous l'Ancien Régime. Colloque de la Casa de Velázquez, París, ADPF, 1981; De l'alphabétization aux circuits du livre en Espagne, XVI et XVII ${ }^{e}$ siècles, París, CNRS, 1987; y los números monográficos de Bulletin Hispanique: La culture des Elites Espagnoles à l'Epoque Moderne, BHi, 97,1 1995; Les livres des espagnols à l'Epoque Moderne, BHi, 99, 1, 1997; Lisantes et lecteurs en Espagne $X^{e}$-XIXe siècle, BHi, 100, 21998.

${ }^{4}$ Máxime Chevalier, «Inventarios de bibliotecas particulares», Lectura y lectores en la España de los siglos XVI y XVII, Madrid, Turner, 1976, págs. 31-36; Jean Michel Laspéras, «Chronique du livre espagnol. Inventaire de bibliothèques et documents de librairie dans le monde hispanique aux XVI ${ }^{\mathrm{e}}$. XVII ${ }^{\mathrm{e}}$ siecles», Revue Française d'Histoire du Livre 28 1980, págs. 535-557; Trevor J. Dadson, «Apéndice 2. Lista de inventarios de bibliotecas particulares», Libros, lectores y lecturas. Estudios sobre bibliotecas particulares españoles del Siglo de Oro, Madrid, Arco Li-
} 
miles de inventarios y otros documentos pertinentes sin publicar $^{5}$, pero, evidentemente, esto resulta inabarcable aquí, y para mis intenciones y propósitos ahora estimo suficiente la amplia muestra estudiada, a la espera del libro de conjunto en prensa ${ }^{6}$. Estudio la presencia de libros de poesía en las bibliotecas que tomo en consideración, desde distintos aspectos. Interesa conocer la proporción de libros de poesía con respecto al número total de los existentes en la biblioteca (aunque esta cuantificación plantea algunos problemas, como se verá después) y dentro de ella me parece también pertinente distinguir, a la luz de lo que hay, entre poetas españoles, latinos, griegos, catalanes, portugueses, franceses, que muestra unos importantes patrones de coherencia y son datos importantes para reconstruir las estimativas del siglo. En este sentido, también podría ser útil comparar con otros géneros literarios, pues ya he realizado esta investigación para novela y teatro ${ }^{7}$ y alguna consideración podré hacer aquí, pero hacerlo de forma sistemática desborda los límites de un artículo, por lo que queda, de nuevo, para el anunciado libro de conjunto ${ }^{8}$.

De especial importancia me parece analizar el significado de las presencias (y ausencias) de poetas en las bibliotecas estudiadas, lo que puede proporcionar datos para acercarse a la realidad del siglo y dar algunas respuestas a las preguntas formuladas más arriba, que, en realidad, responden a obligaciones ineludibles de la historia de la literatura en el complejo camino que va del ayer al hoy. Diré ya que, aparte de distintos patrones valorativos que pueden sorprender con respecto al canon de excelencia construido hoy, hay numerosos autores que no han dejado rastro en la memoria literaria, pero que estaban presentes en las bibliotecas del Siglo de Oro.

bros, 1998, págs. 516-529; Víctor Infantes, François López, Jean-François Botrel, eds., «Bibliografía: primera parte», Historia de la edición y de la lectura en España 1472-1914, Madrid, FGSR, 2003, págs. 787-820; Juan Delgado, «Los catálogos de libreros y editores», Historia de la edición, ed. Víctor Infantes, François López, Jean-François Botrel, págs. 133-141; José Manuel Prieto, Lectura y lectores. La cultura del impreso en el Madrid del Siglo de Oro (1550-1650), Mérida, ERE, 2004; Fernando Bouza, El libro y el cetro. La biblioteca de Felipe IV en la Torre Alta del Alcázar de Madrid, Salamanca, IHLYL, 2005; Carmen Manso Porto, Don Diego Sarmiento de Acuña, conde de Gondomar (1567-1626). Erudito, mecenas y bibliófilo, s. 1., Xunta de Galicia, 1996. Hay algún otro inventario publicado que no he podido tomar en consideración y estudios que he conocido después de redactar este artículo (Dadson, Weruaga, Martín Velasco, Montero Delgado, Ruiz Pérez, etc.).

${ }^{5}$ Francisco Javier Lorenzo Pinar, Florián Ferrero Ferrero, «Fuentes locales para el estudio del libro y de la lectura en Castilla en el siglo XVII: problemas y perspectivas de trabajo», Signo, 13, 2004, págs. 45-62: «más de 9500 inventarios postmortem y de segundas nupcias, almonedas, hijuelas, legítimas y partijas» (pág. 45). Me consta la existencia de estudios en proceso sobre varias bibliotecas, como, por ejemplo, la del conde-duque de Olivares. Me atengo a lo que se indica en nota 4.

${ }^{6}$ José María Díez Borque, Literatura (prosa, poesía, teatro) en bibliotecas privadas del siglo XVII, op. cit.

7 Véase n. 1.

${ }^{8}$ Véase n. 6. 
Soy consciente del cierto enojo que pueden producir los datos numéricos, pero son necesarios, y no se me oculta que tanta operación aritmética haya podido llevar a algún error, que el lector podrá perdonar y subsanar.

No puedo dejar de decir, y no es problema menor, que he debido de manejar la referencia de miles de libros (registros), por lo cual, a pesar de repetidas comprobaciones, ha podido «escaparse» algún autor y obra, por lo que, aunque altere mínimamente las proporciones, pido disculpas anticipadas. Por otra parte, las variadas formas de incorporar obras y autores a los inventarios (véase apartado siguiente) y las menciones, en numerosos casos, de autores y obras que no han dejado rastro en las fuentes de consulta al uso dificultan, enormemente, la consideración de obra poética o no. Pero esto es lo que hay, y me refiero a ello, particularmente, en la «Relación de Inventarios», señalando ya que no puede haber en los datos numéricos una exhaustividad, más fácil en novela y teatro.

No se me oculta que la presencia de libros de poesía en las bibliotecas es sólo una parte de la comunicación poética en el siglo XVII. No puede olvidarse la compleja vida de la poesía en el Siglo de Oro, como estudió Rodríguez Moñino con diferencias entre la realidad poética y su reconstrucción hoy ${ }^{9}$, y el peso de la oralidad en su multitud de formas de romances, canciones tradicionales, etc. Pero está, además, la poesía en la calle de la fiesta y la celebración, y de la protesta en pasquines en verso, que nos lleva a los terrenos de la poesía visual ${ }^{10}$. Además, las academias, el manuscrito ocasional, el teatro en verso, el océano de los pliegos de cordel... Pero sobre todo está también el amplio mundo de los cancioneros poéticos manuscritos, de la poesía no publicada, para la que son imprescindibles las investigaciones de Jauralde Pou y su equipo de investigación ${ }^{11}$. Todo esto enmarca en cuanto a su alcance el significado de la presencia de libros de poesía en las bibliotecas particulares del siglo XVII. Y hay que tener presentes los problemas de las propias fuentes de información,

\footnotetext{
${ }^{9}$ Antonio Rodríguez Moñino, Construcción crítica y realidad histórica en la poesía española de los siglos XVI y XVII, Madrid, Castalia, 1965. Pablo Jauralde Pou, «El público y la realidad histórica de la literatura española de los siglos XVI y XVII», Edad de Oro, I, 1982, págs. 55-63. No entro aquí en los problemas de la oralidad y la importante bibliografía sobre ella.

${ }^{10}$ En varios estudios me he ocupado de ello y de la bibliografía pertinente. Baste citar José María Díez Borque, Verso e imagen. Del Barroco al Siglo de las Luces. Parte Primera, Madrid, Comunidad, 1993 y «Literatura en la calle. Prosa y poesía en las paredes: pasquines del Siglo de Oro español (I)», Bulletin of Hispanic Studies, LXXII, 4, 1995, págs. 365-383. También Culturas en la Edad de Oro, dir. José María Díez Borque, Madrid, Editorial Complutense, 1995, con estudios de Díez Borque, Cid, Frenk, García de Enterría, Schwartz, Simón, López Estrada, López Baralt, Sabat.

${ }^{11}$ Ha de verse Catálogo de manuscritos de la Biblioteca Nacional, con poesía en castellano de los siglos XVI y XVII, dir. Pablo Jauralde Pou, Madrid, Universidad Autónoma de Madrid, Arco Libros, 1998. Hay que tener presentes los trabajos en curso en este sentido y Poesía manuscrita. Manual de investigadores, Edad de Oro, Biblioteca Nacional, dir. Pablo Jauralde, Madrid, Calambur, 2003.
} 
que vamos a ver a continuación, además de que he debido limitarme a lo que hay en los inventarios estudiados (véase n. 4), sin poder atender a otras bibliotecas que están siendo estudiadas, como por ejemplo, la del conde duque de Olivares.

\section{LOS PROBLEMAS DE LAS FUENTES DE INFORMACIÓN}

Muchos son los problemas, de todo tipo, que plantean las fuentes de información. Ya nos hubiera gustado que fueran más rigurosas, detalladas, exactas, pero hay lo que hay, y con estos mimbres ha de fabricarse el cesto. En primer lugar, la tipología de fuentes es variada: inventarios postmortem, en vida, ventas, testamentos, segundas nupcias, almonedas hijuelas, partijas, etc., lo que afecta, claro, a las posibilidades informativas de las mismas ${ }^{12}$. Asumido esto, no es menos importante contar con lo que no está o no puede estar en estas fuentes documentales, en los inventarios, es decir el problema de las ausencias. Retengo lo que escribía en otra ocasión sobre ello:

El profesor Víctor Infantes ha hecho un útil y juicioso balance de los problemas que plantean los inventarios, atendiendo al tipo de bibliotecas, «tipología documental del propio inventario», «clases estamentales» y número de libros, etc. Interesa aquí, sin entrar en cuestiones de lectura, como dije, su análisis de lo que no está en los inventarios, tanto libros prestados, sin valor, omitidos por varias razones, como «lo que no son libros»: relaciones de sucesos, almanaques, calendarios, sermones, oraciones, pliegos sueltos... etc. Por su parte, Chevalier y Dadson abordan el problema, fundamentalmente, desde la relación inventario-lectura, en que, como he repetido, no entro aquí. Pero sí me interesa lo que apunta Dadson sobre que «un inventario no tiene por qué representar todos los libros que una persona ha poseído en su vida», las ausencias de «libros de entretenimiento», diferencias entre el elevado número de ediciones de una obra y lo que los inventarios reflejan, ausencias por mal estado del mucho uso, préstamos, desacuerdos entre el status del poseedor y

${ }^{12}$ Dadson, Libros, lectores, págs. 14 y ss. Lorenzo-Ferrero, «Fuentes», págs. 45 y ss. Víctor Infantes, «Las ausencias en los inventarios de libros y de bibliotecas», Bulletin Hispanique 99, 1, 1997, págs. 281-292. Sobre las características del inventario, función, problemas metodológicos: ídem; «La memoria de la biblioteca: el inventario», El escrito en el Siglo de Oro. Prácticas y representaciones, dir. por Pedro M. Cátedra, Agustin Redondo, María Luisa López-Vidriero, ed. Javier Guijarro Ceballos, Salamanca Universidad, Publications de la Sorbonne, SHEL, 1998, págs. 163-170; Manuel J. Pedraza, «Los estudios sobre inventarios y catálogos de bibliotecas en Aragón en la Edad Moderna», Bulletin Hispanique, 99, 1, 1997, págs. 231-242; ídem, «Lector, lecturas, bibliotecas...: El inventario como fuente para su investigación literaria», Anales de documentación 2, 1999, págs. 137-158; Bartolomé Bennassar, «Los inventarios post-mortem y la historia de las mentalidades», La documentación notarial y la historia: Actas del II Coloquio de Metodología Histórica Aplicada, Santiago de Compostela, Colegios Notariales, 1984, págs. 139-146, y los estudios citados en notas 2,4 y 5 . 
sus libros, dificultad de extraer conclusiones por el reducido número de libros de algunas bibliotecas, etc. ${ }^{13}$

Por su parte, Lorenzo y Ferrero aluden a las «prácticas de préstamo, alquiler y empeño de libros», lo que afecta, claro, al significado e interpretación de lo inventariado. $\mathrm{Y}$ en este sentido Chevalier puntualiza: «la presencia de un libro en una casa no significa gran cosa, o mejor dicho puede significar varias cosas» y lo concreta, después, en la diferencia de lecturas de clérigos y letrados y lo que significan sus bibliotecas especializadas ${ }^{14}$.

Pero no son menores los problemas de cuantificación, identificación y clasificación. Como señalan Lorenzo y Ferrero, a veces hay indicaciones como «mesa de libros», «cajones de libros», no se especifica el número de ejemplares, se dan relaciones incompletas, se da «una cifra monetaria global» ${ }^{15}$. En alguna ocasión se incluye bajo un mismo registro varios títulos, varios volúmenes de un mismo título, se da número global sin especificar títulos, se anota «varios libros», sin más. También se da el caso de volúmenes en que se encuadernan juntas varias obras (a pesar de esto en el estudio utilizo el término «libro», más expresivo, y registro en «Relación de inventarios»).

Hay marcadas diferencias en los inventarios en el modo de citar los libros. En aisladas ocasiones dan título, autor y año de edición. Frecuentemente, dan títulos sólo, autores sólo, indicaciones temáticas genéricas, precisiones sobre las características materiales del libro, títulos en forma aleatoria, referencias genéricas, etc. Encontramos indicaciones como «un libro griego que no hay quien sepa qué libro es» (21, pág. 3); «tres libros de mano antiguos» (31, pág. 110); «un libro de mano que no tiene nombre ni autor» (21, pág. 14). Todo esto dificulta la identificación, por lo que hay que agradecer el esfuerzo de algunos editores modernos de los inventarios para establecer, con los datos a mano, la obra de que se trata, siempre, claro, con un insalvable margen de error. Lorenzo y Ferrero enfatizan las dificultades de establecer la edición concreta de que se trata por esta forma de citar por temas, lengua, estado de conservación, tipografía, alusiones genéricas, autor, incluso cuando se cita autor y título resumido ${ }^{16}$.

Una gran mayoría de los inventarios estudiados aquí no ofrecen clasificaciones temáticas, pero hay unos pocos casos en que sí lo hacen, lo que nos sitúa ante un apasionante problema cultural que merecería detenido estudio, para

13 Díez Borque, «Novelas en bibliotecas», Arkadien, pág. 191. Para las obras citadas: Infantes, «Las ausencias», págs. 281 y ss; Chevalier, «Inventarios», págs. 31-36; Chevalier, «Lecturas y lectores... veinte años después», Bulletin Hispanique, 99, 1, 1997, págs. 14-24; Dadson «Apéndice 2» y «Las bibliotecas particulares en el Siglo de Oro», Historia de la edición, cita en n. 4, págs. 123-132. Son pertinentes los estudios citados en notas 4 y 12.

14 Lorenzo-Ferrero, «Fuentes», pág. 49; Chevalier, Lecturas, passim.

15 Lorenzo-Ferrero, «Fuentes», págs. 47 y ss.

16 Ibídem, págs. 54-55. 
el que no hay espacio ni ocasión aquí. En todo caso, valga decir que la ordenación de temas que es toda clasificación ofrece datos impagables para la historia cultural del período en cuanto al modo de acotar y acuñar los saberes. Pero no es esto, como queda dicho, lo que aquí interesa, sino, una vez más, los problemas que estas clasificaciones presentan, que no son pocos, y llevan a confusión, a la hora de utilizarlas para separar la literatura en sus diversos géneros de otros tipos de libros (Historia, Derecho, Filosofía, Cosmografía, Matemáticas, Religión, Geografía, etc.).

Encontramos así, por ejemplo, obras literarias bajo el epígrafe «Historia romana», (26) «Diversos de Teología y Humanidad» (27), aunque pueden orientar clasificaciones del tipo «Letras humanas» (26 y 59), «Buenas letras» (63), etc. Pero el más cumplido testimonio de las dificultades que ofrecen las clasificaciones temáticas para aislar las obras literarias del conjunto de libros nos lo ofrecen los inventarios de dos bibliotecas singulares: la del conde de Gondomar y la de Felipe IV. Encontramos en ambas, junto a una gran variedad de temas, clasificaciones específicamente literarias, que parecería que acotan el terreno de la literatura y dentro de ella el de los distintos géneros, pues tal especificación se hace en ocasiones. Pero no siempre es así. Como mero testimonio orientativo valga decir que en la del conde de Gondomar, bajo el epígrafe «Libros de poesía en griego» se incluye el teatro de Aristófanes, Sófocles, Eurípides. En «Libros de poesía en latín» a Terencio, Séneca. En «Libros de poesía en español» aparece Florando de Castilla, la Diana de Montemayor, la segunda parte de Alonso Pérez, etc. En la de Felipe IV en «Poetas latinos traducidos»: Plauto, Terencio; en «Poetas españoles»: Cárcel de amor de San Pedro, Diana de Montemayor, Dorotea y Arcadio de Lope de Vega, etc. Bouza analiza cumplidamente el significado, alcance y problemas de la clasificación por materias de la biblioteca de Felipe IV —allí remito— descubriéndonos, por ejemplo, «duplicaciones», como en el caso de Barros, «practicidad» de la clasificación, ausencias como en el caso de Herrera y Jáuregui, etc. Manso Porto apunta el problema de que las obras de algunos escritores «estuviesen encuadernadas formando colecciones con poemas de otros autores», incluso en obras en prosa ${ }^{17}$. Esto recalca los problemas de las fuentes de información, como venimos viendo, y subraya la dificultad de que las menciones, proporciones, etc., alcancen un grado de exactitud. Por otra parte, el elevado número de libros incluidos en estos inventarios y la mención de obras muy complejas de identificar hacen difícil la separación genérica desde los criterios de la historia de la literatura, especialmente en el caso de las bibliotecas del conde de Gondomar y Felipe IV. Por si fueran pocos, todavía hay otros problemas que plantean los inventarios, que enumero, siguiendo las

${ }^{17}$ Bouza, El libro, págs. 73 y ss.; 78; 121. Manso, Don Diego, pág. 55. Escribe Bouza «hay cuarenta y cinco obras que aparecen en más de una materia a pesar de tratarse de un único volumen» (pág. 47). 
puntualizaciones de Lorenzo y Ferrero: «representatividad social frente al conjunto poblacional», «difícil establecer categorías socioprofesionales», «visión fundamentalmente urbana del ámbito de la lectura o de la posesión de libros», «distinguir qué libro de los inventarios masculinos o del matrimonio eran objeto de lectura de la mujer», «no abarcaba todas las pertenencias» ${ }^{18}$, etc.

No todos los problemas enunciados hasta aquí afectan del mismo modo al objetos de esta investigación, pero parecía oportuno recoger estas cautelas, remitiendo a la «Introducción y explicación», a «Relación de inventarios» para problemas específicos del estudio que aquí se ofrece. Tras esta cura en salud, justa y necesaria, no estará de más decir que hay un importante volumen de datos ciertos sobre el significado de la presencia de poesía en bibliotecas particulares del Siglo de Oro, que cada lector podrá interpretar y utilizar según sus intereses, sin entrar yo aquí, pues no es mi propósito, en la valoración de una ya rica bibliografía sobre bibliotecas ${ }^{19}$ ni internarme en los resbaladizos y peligrosos, por conjeturables, terrenos de la lectura ${ }^{20}$.

\section{LIBROS DE POESÍA EN LAS BIBLIOTECAS}

Parece oportuno distinguir, en primer lugar, entre las bibliotecas en que no aparece poesía y las que sí la incorporan a sus fondos, para valorara después proporciones y significados.

\subsection{Bibliotecas sin libros de poesía}

De las 65 bibliotecas particulares estudiadas nos falta inventario completo de cinco $(10 ; 28 ; 33 ; 50 ; 61)$ por lo que cuento al efecto 60 bibliotecas. No encuentro libros de poesía en doce $(2 ; 4 ; 11 ; 12 ; 13 ; 17 ; 24 ; 25 ; 37 ; 40 ; 47$; 58). Esto supone un $20 \%$ de bibliotecas sin poesía, lo que quiere decir que en $80 \%$ de las bibliotecas sí había libros de poesía. Es una proporción muy importante y reveladora, aunque habrá que reconsiderarla más adelante, al valorar la proporción de libros de poesía con respecto al número total de los que integran la biblioteca.

Si comparamos con las ausencias de novela y libros de teatro en las bibliotecas estudiadas resalta significativamente el peso de los libros de poesía en esas bibliotecas. No aparecen novelas en los fondos de 26 bibliotecas, y teatro en los de 37 , lo que destaca visiblemente con respecto a las doce en que no hay poesía, como dije ${ }^{21}$.

\footnotetext{
${ }^{18}$ Lorenzo-Ferrero, «Fuentes», págs. 46 y ss.

19 Véase n. 2.

20 Véase n. 3.

21 Véase n. 1
} 
En su lugar me refería a alguna de las razones de ello. Lo que interesa ahora es la simple constatación del destacado mayor peso de los libros de poesía, como veremos después, aun a pesar de las peculiares circunstancias de su difusión (oralidad, manuscritos, pliegos de cordel...). No cabe extraer conclusiones por área geográfica, período, clase social, sexo (ya me refería a estos problemas en el apartado 2). Constatamos que las bibliotecas sin poesía pertenecen a distintos sectores socioprofesionales (pero lo mismo ocurre con las que sí la tienen): gentilhombre de cámara (2); pintor (11); abogado (13); platero (17); condesa (24); obispos (25 y 40); agente de negocios (47); duquesa (58), etc.

En cuanto a la presencia de novela y teatro en estas bibliotecas sin poesía tenemos que de las que no tienen poesía, solamente en la del agente de negocios López de Olivares aparecen novelas de Camerino, Lope de Vega y Castillo Solórzano, y en ninguna de ellas libros de teatro.

Podría ser interesante intentar dar respuesta a la pregunta ¿qué hay en las bibliotecas en que no hay poesía? No es posible aquí un estudio sistemático, que exigiría el análisis detallado de cada una de las bibliotecas, rastreando, además, la presencia de la misma obra en varias y el significado de lo que hay.

No obstante, como mera orientación aquí, baste remitir a lo que dije sobre los libros que rodean en las bibliotecas a los libros de novela española. Eso nos proporciona una aproximación al cómo estaban constituidas las bibliotecas. Pero no se me oculta la necesidad de afinar más para reconstruir el mundo del libro en las bibliotecas sin poesía, como he dicho.

\subsection{Bibliotecas con libros de poesía}

Me parece bastante contundente y significativo el dato de que en 48 bibliotecas de las 60 consideradas sí hay libros de poesía $(80 \%)$. Significa esto que son muchas más las bibliotecas con libros de poesía que las que no cuentan con ellos en sus fondos, frente a lo que ocurre con novela y teatro, como vimos. Antes de entrar en la valoración de las proporciones de los libros de poesía con respecto al número total de libros de cada biblioteca, que nos dará el peso real de la poesía en bibliotecas particulares estudiadas del siglo XVII, puedo retener aquí, como términos de comparación, lo que escribí sobre novela en este sentido:

Si consideramos el número de bibliotecas en que no hay novelas, el menor número de éstas en que sí hay y las reducidas proporciones con respecto a los libros que integran la biblioteca podemos tener una idea del poco peso y significado de la novela en las bibliotecas particulares del Siglo de Oro, sin entrar aquí, de nuevo, en cuestiones de lectura, a lo que ya me referí» ${ }^{22}$.

\footnotetext{
${ }^{22}$ Díez Borque, «Novelas en bibliotecas», Arkadien, pág. 105.
} 
Y todavía es más importante y significativo todo esto en cuanto a libros de teatro, destacando, además, la ausencia de autores españoles del propio siglo XVII, lo que nos lleva a los resbaladizos terrenos de las relaciones lectura-representación, como estudio en otro lugar ${ }^{23}$.

Pero tras constatar la presencia de libros de poesía en las bibliotecas — con las elevadas cifras vistas - hay que tomar en consideración las proporciones con respecto al conjunto de libros en cada biblioteca, para valorar el peso de la poesía en ellas. Prescindiendo de la del conde de Gondomar (más de 6471 libros) y de la de Felipe IV (más de 2000 libros) que trataré separadamente, por sus especiales características (cuento, pues, 58), tenemos los siguientes porcentajes -sin exhaustividad, como ya dije- de libros de poesía con respecto a los existentes en las bibliotecas (en otro apartado lo veremos por áreas culturales):

$\longrightarrow$ Inferior al $1 \%: 18 ; 22 ; 27 ; 53: 6,89 \%$ de las bibliotecas.

$\rightarrow$ Del $1,1 \%$ al $3 \%: 9 ; 19 ; 26 ; 32 ; 42 ; 49 ; 59: 12,06 \%$ de las bibliotecas.

$\rightarrow$ Del $3,1 \%$ al $5 \%: 16 ; 30 ; 31 ; 43 ; 45 ; 52 ; 54 ; 62: 13,79 \%$ de las bibliotecas.

$\rightarrow$ Del 5,1 \% al $7 \%: 1 ; 7 ; 29 ; 39 ; 57: 8,62 \%$ de las bibliotecas.

$\longrightarrow$ Del $7,1 \%$ al $9 \%: 3 ; 5 ; 20 ; 21 ; 41 ; 44 ; 48 ; 51 ; 63 ; 65: 17,24 \%$ de las bibliotecas.

$\rightarrow$ Del 9,1\% al $11 \%: 15 ; 56 ; 64: 5,17 \%$ de las bibliotecas.

$\longrightarrow$ Más de $11 \%: 6 ; 8 ; 14 ; 34 ; 36 ; 38 ; 46 ; 60: 13,79 \%$ de las bibliotecas.

Por los datos apuntados se comprueba que en cuatro bibliotecas la presencia de poesía es inferior al $1 \%(6,89 \%)$; en siete entre $1,1 \%$ y $3 \%(12,06 \%)$; en ocho entre $3,1 \%$ y $5 \%(13,79 \%)$; en cinco entre $5,1 \%$ y $7 \%(8,62 \%)$; en diez entre $7,1 \%$ y $9 \%(17,24 \%)$; en tres entre $9,1 \%$ y $11 \%(5,17 \%)$; en ocho más del $11 \%(13,79 \%)$. En términos absolutos muestra esto que, aunque la presencia de poesía es importante, como hemos visto, en cuanto al número de bibliotecas, no lo es tanto en cada una de ellas, con respecto al número de libros que las integran, pues en $35(60,34 \%)$ es inferior al 9,1\%; solamente en tres está entre el 9,1 y $11 \%$ y en ocho supera el $11 \%$, sobrepasando el $20 \%$ sólo en dos y sin llegar al $25 \%{ }^{24}$. Pero no se me oculta que una comparación en

23 Véase n. 1.

${ }^{24}$ Inferior al $1 \%$ : $18(0,90) ; 22(0,23) ; 27(0,71) ; 53(0,49)$

— del 1,1 \% al $3 \%$ : $9(2,43 \%) ; 19(1,96 \%) ; 26(1,38 \%) ; 32(2,89 \%) ; 42(2,16 \%)$; $49(2,63 \%) ; 59(1,65 \%)$

— del 3,1\% al $5 \%$ : $16(3,29 \%), 30(3,44 \%) ; 31(4,91 \%) ; 43(3,22 \%) ; 45(4,44 \%)$; $52(3,84 \%) ; 54(4,83 \%) ; 62(3,44 \%)$

— del 5,1\% al $7 \% ; 1(5,17 \%) ; 7(6,62 \%) ; 29(5,07 \%) ; 39(6,31 \%) ; 57(5,79 \%)$

- del 7,1 \% al $9 \%$ : $3(8,33 \%) ; 5(8,69 \%) ; 20(8,69 \%) ; 21(8,02 \%) ; 41(7,44 \%) ;$ $44(7,61 \%) ; 48(7,89 \%) ; 51(7,50 \%) ; 63(8,11 \%) ; 65(7,14 \%)$ 
este sentido con otros géneros literarios ${ }^{25}$ y otro tipo de materias matizaría estos datos, aunque sin restarles, creo, valor en sí mismos.

Como indiqué, las bibliotecas del conde de Gondomar y Felipe IV merecen una consideración aparte. Tanto por el elevado número de libros, que les da un carácter atípico en el conjunto de las bibliotecas estudiadas, como por los problemas que plantean las clasificaciones por materias de estas bibliotecas y las obras incluidas en cada una de ellas, con problemas, además, de duplicaciones, disparidad según nuestros criterios actuales, como vimos, etc. Pero hay una dificultad importante de cuantificación, más acusada, quizás, en la biblioteca del conde de Gondomar, por la cantidad de obras, particularmente españolas, a las que es complejo dar una adscripción genérica, por problemas de identificación. Por todo esto no me parece aconsejable ofrecer las cuantificaciones y proporciones, como he hecho con las otras bibliotecas. Baste apuntar que en la biblioteca del conde de Gondomar, según la editora de su inventario, Manso Porto, había «unos seiscientos libros de poesía impresos; de ellos 450 en castellano; 106 en italiano; 27 en portugués y los menos en francés e inglés, catalogados con varias materias. A ellos habría que sumar los manuscritos agrupados en el apartado Libros de poesía, comedias y historias fabulosas», y no se mencionan los libros de poesía en griego, en latín y alguno en otros apartados del índice de materias ${ }^{26}$. Por su parte, en la de Felipe IV, Bouza analiza cada una de las materias que propone el inventario, dando el número de títulos y cuerpos, así: nueve entradas (poetas griegos); 27 (latinos); 114 (españoles); 79 (italianos y franceses); 245 («libros varios de diversas lenguas»), pero él mismo apunta, como vimos, los problemas de esta clasificación por materias, y ya hemos visto duplicaciones, ausencias..., además de la inclusión bajo epígrafes de poesía, de novela, teatro, que no estudio aquí ${ }^{27}$. Pero, claro está, hay que tener en cuenta la condición socioprofesional de los poseedores.

Como ya dije, no puedo hacer aquí un estudio detallado de los libros que «rodeaban» a los de poesía en las bibliotecas consideradas, ni detenerme en cada biblioteca particular, por más que ello ofreciera datos importantes para valorar el peso y significado de la poesía en estas bibliotecas. Prescindiendo de la presencia de novela y teatro, que estudio en otro lugar, tenemos que:

No faltan en las bibliotecas, como venimos viendo, los grandes núcleos habituales: el religioso, el clásico, el histórico, el político, justificados per se. Encontramos el libro religioso con su variedad de posibilidades: Kempis, San

— del 9,1\% al $11 \%: 15(10,52 \%) ; 56(10,34 \%) ; 64(9,80 \%)$

— más del $11 \%: 6(18,51 \%) ; 8$ (17,77\%); 14 (24,07\%); 34 (20,22\%); 36 (14,89\%); 38 $(11,42 \%) ; 46(11,76 \%) ; 60(16,66 \%)$

${ }^{25}$ Véase n. 1.

${ }^{26}$ Manso, Don Diego, pág. 58.

${ }^{27}$ Bouza, El libro, págs. 73 y ss.; 113; 118-119; 120; 139. 
Ambrosio, San Agustín, Santo Tomás, Santa Teresa, San Jerónimo, San Ignacio, San Juan, vidas de santos [...]

Libros de ciencias aplicadas (Arquitectura, Geometría, Matemáticas, Derecho, Medicina, Cocina...) hay en varias bibliotecas $(1 ; 16 ; 20 ; 45 ; 46 ; 64 . .$.$) . Así$ mismo no faltan retóricas, gramáticas, con importante presencia de Nebrija $(6 ; 14 ; 16 ; 31 ; 44 ; 51 \ldots)$, ni libros de música $(44 \ldots)$; lunarios (46...); Filosofía (7...).

Obras misceláneas, como la Silva de Mexía, tienen un lugar destacado (1; 7; $14 ; 16 ; 30 ; 34 ; 46 \ldots)$, también aparece Guevara $(34 ; 38 ; 39 ; 51 \ldots)$; Torquemada $(38 . .$.$) ; refraneros (7...) etc. Las obras del propio Erasmo, que tanto$ tuvo que ver - sin entrar aquí en polémicas sobre el erasmismo- en la difusión de este tipo de literatura aparece en varias bibliotecas $(14 ; 38 ; 39 ; 51 \ldots)$, etc. (Díez Boeque, Literatura en bibliotecas particulares, citado).

Muy significativo es, por ejemplo, en el conjunto de las bibliotecas, contando también aquellas en que no hay poesía, la presencia de Flos Sanctorum de Villegas $(1 ; 2 ; 4 ; 6 ; 18 ; 24 ; 25 ; 29 ; 30 ; 31 ; 56 ; 58 .$.$) o de Ribadeneyra (3 ; 18$; $24 ; 25 ; 32 ; 42 ; 52 ; 56 ; 58 .$.$) , además de libros de salmos: 8 ; 9 ; 14 ; 18 ; 20 ; 24$; $38 ; 39 ; 42 ; 43 ; 44 ; 49 ; 51 ; 64 .$. Pero no parece aconsejable ir aquí más lejos en estas particularizaciones.

Los índices de la época de materias de la biblioteca del conde de Gondomar y de la de Felipe IV, excepcionales, nos proporcionan una valiosa y sugestiva guía de los fondos posibles de las bibliotecas particulares del Siglo de Oro. Así, en la del conde de Gondomar, prescindiendo de la clasificación de los abundantes libros en hebreo, griego, latín, italiano, francés, inglés, portugués, catalán, manuscritos en varias lenguas, prohibidos, tenemos:

Historia de los reyes y reynos de España

Historias de las Indias de Castilla y Portugal

Historias de los estados de Flandes y Holanda

Historias de los griegos y de los romanos

Historias universales y de otras differentes cosas

Historias de Francia, Alemania, Italia, Polonia, etc.

Historias de los judios, turcos, persas, y de las cosas de África

Historias sagradas

Estatutos y chrónicas de las tres órdenes de Calatraua, Alcántara y Santiago

Constituciones sinodales de differentes obispados y universidades y collegios de España

Libros tocantes a las cosas diuinas

Libros de Medicina y Alueytería

Libros de Arithmética, Geometría, Astronomía, etc.

Libros del arte de navegar 
Libros de Architettura

Libros del arte militar

Libros de Música

Libros de differentes sciencias y otras cosas varias

Leyes y ordenanzas de los reynos d'España

Cortes de los reynos d'España, etc.

Libros de cauallería o historias fabulosas

Libros de poesía

Obras de Lope de Vega y comedias de differentes autores

Libros de exequias, reciuimientos y fiestas que se han hecho a reyes y príncipes

(Manso) (Díez Borque, Ibídem)

En la de Felipe IV:

Índice de las materias que se contienen y a que se reducen todos los libros

Crónicas universales del Mundo

Historias de España y Castilla

Leyes del Reyno

Historias de Ciudades y Obispados de España

Historias de los Reynos de Aragón, Valencia, Cataluña, Sardeña, Navarra y Vizcaya

Del Reyno de Portugal y su India, China, Japón, Philipinas y Etiopía Historia de las Indias Occidentales

Historia de África y Turquía

Historia de Persia

Historia de Polonia, Bohemia, Ungría, Transilvania, Dinamarca y Suecia

Historias de Inglaterra y Escocia

Historias Francesas

Historia Italiana

Historia y Guerras de Flandes y Alemania en Italiano y Castellano

Nobleza y linages de España y otras partes

Historia de Personas señaladas

Órdenes Militares y del Tusón

Milicia, Artillería y Fortificación

Arquitectura, Pintura, Escultura, Medallas y Estampas

Cosmografía, Geografía y Topografía

Esfera

Matemáticas, Astronomía, Aritmética, Perspectiva y Astrología Hydrographía 


\author{
Filosofía Natural y Moral y Racional \\ Medicina, Botica y Yerbas, Cirugía, Anatomía \\ Govierno y Estado \\ Historiadores Griegos traducidos \\ Poetas Griegos traducidos \\ Historiadores Latinos traducidos en Romance, Italiano y Francés \\ Poetas Latinos, traducidos \\ Poetas Españoles \\ Poetas Italianos y Franceses \\ Diccionarios y Gramáticas \\ Retórica y Poética \\ Teología Positiva y Moral \\ Historia Eclesiástica \\ Libros de Devoción y Piedad \\ Música \\ Agricultura \\ Libros varios de diversas lenguas
}

$(\text { Bouza })^{28}$ (Díez Borque, Ibídem)

Los inventarios de alguna otra biblioteca corroboran y complementan este panorama de posibilidades, que recojo sólo como síntoma, pues lo que nos interesa, claro está, es la poesía. Tenemos así en el inventario 26: «Historia en latín; Historia en romance; Libros de Teología; Letras humanas; Libros de leyes y cánones; Libros griegos». En el 27: «Lecturas civiles; Lecturas canónicas; Tratados; Decisiones; Consejos; Prácticas; Diversos de cánones y leyes; Diversos de Teología y Humanidad». En el 53: «Libros del Reino; Libros de Inquisición; Libros de Humanidad; Teología moral; Historia», pero también «Libros de a $4^{\circ}$; Libros de a octavo». En el 59: «Lecturas canónicas; Consejos; Libros de leyes; Libros italianos». Pero, claro está, hay que tener en cuenta la condición socioprofesional de los poseedores.

Lo mismo que decía para las bibliotecas sin poesía en cuanto a la relación con la clase social y el sexo, puedo repetir aquí para las bibliotecas con libros de poesía. No es posible establecer una relación explicativa entre clase social, nivel cultural, sexo, medio urbano o rural y posesión de libros de poesía, con los datos a mano aquí. El hecho cierto es que libros de poesía aparecen en la biblioteca del rey Felipe IV (55) y de damas y caballeros de la nobleza: duquesa de Béjar (1); condesa de Salinas (9); conde de Puñonrostro (16); condestable Fernández de Velasco (21); Pacheco, caballero de Calatrava (32); conde de Gondomar (45); duque de Pastrana (36); condesa de Lemos (42); conde de Sa-

${ }^{28}$ Ibídem, págs. 196-198. La cita de Manso, Don Diego, págs. 634 y ss.; la de Bouza, El libro, págs. 169 y ss. 
linas (44); conde de Benavente (51); marquesa de Auñón (56); conde de Guimerá (57). Además de la importante proporción destaca el hecho de que aparezcan tanto damas como caballeros nobles, lo que no ocurrirá en otros sectores, como veremos.

Encontramos poesía en bibliotecas de autoridades y cargos públicos: regidor Peralta (27); protonotario Villanueva (29); capitán, Soto (43); secretario de Su Majestad, Fernández (49); inquisidor Salazar (53); contador de resultas, González (54). Y en las de «profesiones liberales»: arquitecto Gómez Mora (20); maestro Álvarez (39); escritor Caro (63). Y no falta en la de gentes de hábitos: capellán Danes (19); arcediano Castillo (26); presbítero López (52); capellán de Felipe IV, Testay (59).

Pero quiero destacar, porque me parece importante, la frecuencia con que encontramos libros de poesía en bibliotecas de las que podríamos considerar «clases trabajadoras» — claro que no en sus estratos más humildes-, fuera, pues, de los ámbitos de la nobleza, el poder, la religión o las actividades liberales, lo que puede aportar datos para el siempre complejo problema de la recepción literaria. Estoy refiriéndome a agentes de negocios, mercaderes, plateros... Valga esta muestra sintomática: agentes de negocios, Lucenberg (3), López (47); plateros, Arfe (5), Carrión (14); mercaderes, Benito (34), Arnolfo (64); bordador, Rutierier (15); guantero, Moreno (38); cordonero, Ayllón (46).

No deja de ser apasionante, aunque no se me oculta que habrá que recolectar muchos más datos, esta presencia de la poesía en los diversos estratos socioculturales de la España del siglo XVII, y más allá, claro, los inabarcables mundos de la voz, el manuscrito, el papel ocasional, la poesía en la calle de fiestas y celebraciones, pasquines, pliegos de cordel, como ya dije, etc.

\section{LOS POETAS Y SUS OBRAS}

Una vez que hemos considerado las proporciones de los libros de poesía en las bibliotecas, lo que es importante para valorar la recepción del género en el Siglo de Oro con unos cuantos datos «ciertos», interesa conocer qué autores, qué obras y de qué áreas culturales estaban presentes en las bibliotecas y en qué proporción. Esto me parece fundamental para establecer las diferencias entre el canon de excelencia construido por la historia de la literatura, es decir, la memoria literaria, y la realidad del siglo, el canon de la época. Con todas las limitaciones que se quiera. Particularmente, es importante esto en cuanto al peso de la poesía española en relación con la latina y la italiana, y también en cuanto a la repetición de varios autores, la significativa ausencia de otros y la presencia de unos cuantos que no ocupan lugar hoy en las historias de la literatura.

Antes de entrar en el canon de excelencia de autores y su valoración, creo necesario, aunque pueda resultar enojosa la acumulación de referencias, presen- 
tar datos comparativos de proporción de la poesía castellana, catalana, portuguesa, latina, griega, italiana, francesa, flamenca, lo que nos dará, antes de pasar a los autores, una necesaria visión global. Me limito ahora a la frecuencia de libros de poesía de distintas áreas culturales con relación al número total de libros de poesía en cada biblioteca, una vez que vimos más arriba la frecuencia global de libros de poesía con respecto al número total de libros que integran la biblioteca. No se me oculta que podrían tomarse en consideración las proporciones de los libros de poesía de cada área cultural con respecto al número total de libros que integran la biblioteca. Tendríamos así especificadas las proporciones de la poesía de cada área cultural en el conjunto de la biblioteca, pero haría más enojosa tanta suma de datos numéricos. Baste por ahora con valorar comparativamente el peso de la poesía castellana, catalana, portuguesa, latina, griega, italiana, francesa, flamenca, que nos permitirá después construir e interpretar el canon de excelencia que «construyen» las bibliotecas estudiadas. Como no interesa aquí el estudio individual de las bibliotecas, prescindo de las comparaciones de presencia de poesía por áreas culturales en cada una de ellas, aunque reconozco también la posible utilidad de estos datos. No entro en cuestiones de traducción o lengua original, pues lo que interesa son las obras.

Es significativa la presencia de poesía castellana, latina e italiana y mucho menos importante la catalana, portuguesa, griega, e irrelevante la de otras áreas culturales. Creo que son datos contundentes el que en las bibliotecas con poesía (48) poesía castellana aparezca en 40 bibliotecas (83,33\%), latina en 34 $(70,83 \%)$ e italiana en $28(58,33 \%)$, sin entrar, como dije, en distinciones de lengua original o traducción. Frente a ello, tenemos, en el área peninsular, que poesía catalana hay en siete bibliotecas, lo que es importante, pero de un solo autor (Ausias March) (14,58 \%), portuguesa en ocho (16,66 \%). Fuera del área peninsular, aparte de los autores griegos a que me referiré después, la poesía en otras lenguas (francés, flamenco) no es significativa.

Especial consideración merece el caso de la poesía griega, por su muy reducida presencia, frente a la poesía latina, con lo que se corrobora el reducido peso de la cultura clásica griega, como estudia Luis Gil ${ }^{29}$. Solamente en diez bibliotecas $(20,83 \%)$ encuentro poetas griegos, y de forma significativa sólo en la del gran bibliófilo conde de Gondomar (35), pues incluso en la de Felipe IV (55) sólo encuentro Museo, Anacreonte y Homero, y en el resto de bibliotecas, exceptuando Homero, apenas es relevante la presencia de autores importantes como Anacreonte, Píndaro, Teócrito, Hesíodo, por no citar a alguno secundario, que aparece aisladamente.

Limitándome, después de lo escrito hasta aquí, a los tres grandes bloques — poesía castellana, latina, italiana- puedo destacar algún hecho importante y

\footnotetext{
${ }^{29}$ Luis Gil Fernández, Panorama social del humanismo español: 1500-1800, Madrid, Alhambra, 1981.
} 
revelador. En nueve bibliotecas $(9 ; 22 ; 23 ; 30 ; 3249 ; 54 ; 56 ; 65)$ sólo hay poesía castellana; en cinco sólo poesía latina $(1 ; 5 ; 19 ; 27 ; 62)$ y en una sólo poesía italiana (53). Lo habitual es la confluencia de las tres, claro que en proporciones variables. Aunque tengo hecho el cálculo de proporciones, resultaría prolijo una vez más dar aquí los datos comparativos. Prescindiendo por las razones ya apuntadas más arriba de las bibliotecas del conde de Gondomar (35), de Felipe IV (55) y de P. Aracil (23) sin número de libros para la castellana, sólo diré que en el caso de la poesía castellana hay once bibliotecas en que la proporción con respecto a los libros de poesía supera el $50 \%(9 ; 22 ; 30 ; 32$; $38 ; 41 ; 44 ; 49 ; 54 ; 56 ; 65)$; en trece está entre el $25,1 \%$ y el $50 \%(3 ; 6 ; 7 ; 8$; $15 ; 29 ; 34 ; 39 ; 42 ; 43 ; 45 ; 46 ; 60)$; en diez va del $10 \%$ al $25 \%(14 ; 16 ; 18$; $20 ; 26 ; 31 ; 36 ; 42 ; 57 ; 59)$ y en cuatro inferior al $10 \%(21 ; 51 ; 63 ; 64)$. En cuanto a la poesía latina, para que pueda compararse, tenemos que en doce bibliotecas supera el $50 \%$ con respecto a los libros de poesía $(1 ; 5 ; 14 ; 18 ; 19$; $26 ; 27 ; 29 ; 39 ; 52 ; 62 ; 63)$; en diez está entre el $25,1 \%$ y el $50 \%(3 ; 6 ; 7 ; 8$; $21 ; 31 ; 43 ; 48 ; 51 ; 60)$; en siete va del $10 \%$ al $25 \%(16 ; 20 ; 38 ; 42 ; 45 ; 46$; $59)$; en tres, menos de $10 \%(34 ; 36 ; 64)$. Por fin, en cuanto a la poesía italiana tenemos que en seis bibliotecas su presencia es superior al $50 \%(16 ; 36 ; 42$; $48 ; 53 ; 59 ; 64)$; en ocho está entre el $25,1 \%$ y el $50 \%(7 ; 15 ; 21 ; 31 ; 34 ; 51$; $60)$; en diez va del $10 \%$ al $25 \%(6 ; 14 ; 18 ; 29 ; 38 ; 39 ; 44 ; 45 ; 46 ; 57)$ y en dos, inferior al $10 \%(8 ; 63)$.

Comparar las proporciones por áreas culturales entre bibliotecas arrojaría luz sobre el peso de la poesía castellana, latina e italiana en las bibliotecas estudiadas, pero, como queda dicho, desborda esto los límites de este estudio. Con todo, los datos recogidos muestran, comparativamente, el significado de la presencia de la poesía de las tres áreas culturales importantes: castellana, latina, italiana.

El estudio de la frecuencia con que aparecen los poetas en las bibliotecas, y el número de ejemplares de sus obras, permite elaborar un canon de excelencia - que puede responder a las estimativas del siglo_- posibilitando la comparación con lo que ha retenido la memoria literaria y construido la historia de la literatura. Permite, además, al tomar en consideración distintas áreas culturales, reconstruir el canon de excelencia de cada una de ellas, en particular de la castellana, latina e italiana, que son las que tienen una presencia importante, como vimos. Las presencias llevan, naturalmente, a valorar las ausencias, con datos significativos, especialmente en cuanto a los poetas en castellano consagrados por el canon de excelencia en nuestro siglo.

Los diez poetas por orden de importancia en cuanto a su presencia en las bibliotecas estudiadas (doy el número de apariciones y entre paréntesis el número de ejemplares en total en el conjunto de las bibliotecas aunque pueda haber alguna variación por las razones apuntadas en el apartado 2) son: 


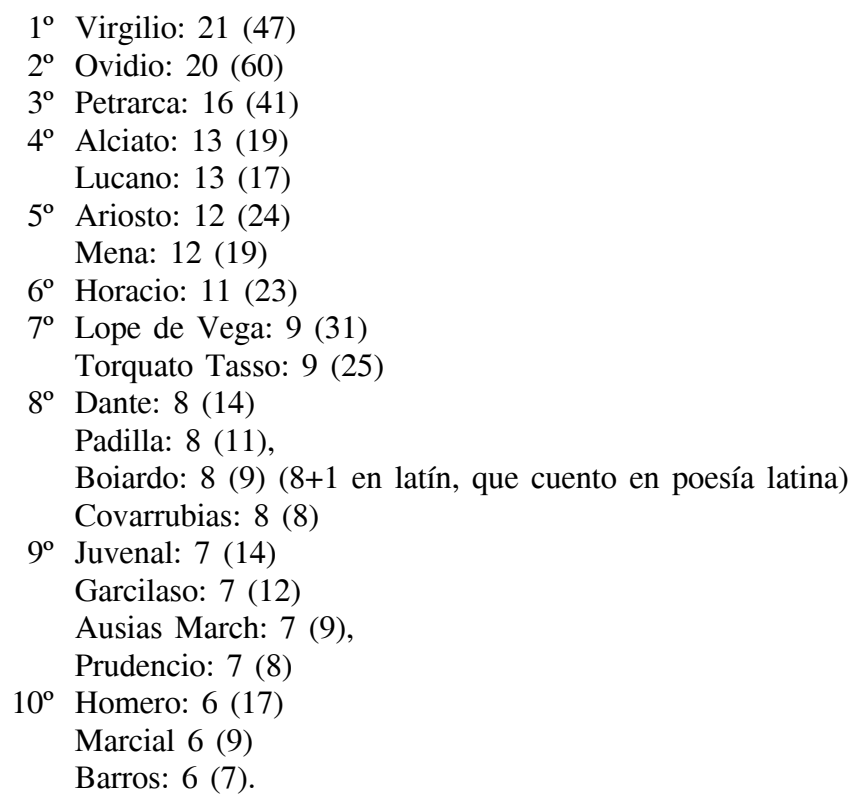

Todavía en cinco bibliotecas - puesto $11^{\circ}$ - encontramos la obra de varios poetas: Romanceros (13); Camoens (11); Marqués de Santillana (8); Catulo (5); Espinosa (5). A partir de aquí tenemos la larga lista de poetas que aparecen en una sola biblioteca y la más reducida la de los que lo hacen en dos, tres y cuatro bibliotecas, a lo que me referiré después. Vayamos ya a lo que significa este «canon de excelencia» de poetas en bibliotecas españolas del siglo XVII.

Los datos son tan contundentes que se comentan por sí solos. Hasta el puesto quinto, con la presencia de Juan de Mena en doce bibliotecas con 19 ejemplares no aparece ningún poeta español y, además, no se trata de ningún poeta contemporáneo, sino de un autor del siglo XV. No volvemos a encontrar poetas españoles hasta el puesto séptimo - nueve bibliotecas-, con el hecho muy significativo de las estimativas del siglo y las diferencias con el canon construido por la memoria literaria de que junto al gran poeta Lope de Vega (31 ejemplares) (puesto $7^{\circ}$ ) aparecen en el puesto octavo autores como Padilla y Covarrubias (11 y 8 ejemplares). Garcilaso aparece en el puesto noveno - siete bibliotecas, 12 ejemplares- y Barros en el décimo $(6 ; 7)$ y nada más de poesía castellana en los diez primeros puestos (el poeta valenciano Ausias March aparece también en noveno lugar, siete bibliotecas con 9 ejemplares). Conviene recapacitar entonces sobre lo que nos descubre este canon de excelencia, pues es la poesía latina e italiana, y no la española, la que ocupa los principales puestos. Sin hacer aquí una nómina de ausencias destacadas, que estaría fuera de lugar, aunque resultara orientativa, resalta el hecho de que Que- 
vedo sólo aparece en una biblioteca, igualado con una larga lista de poetas de segunda y tercera fila, que no detallo aquí (véase «Relación de Inventarios»). Poetas de la talla de Hernando del Castillo, Castillejo, fray Luis de León, Cueva, Enzina..., están presentes sólo en dos bibliotecas. Y un Jorge Manrique, San Juan de la Cruz, Góngora, Herrera, Cervantes, sólo los he encontrado en tres bibliotecas, con la misma categoría, en este sentido, que Fuentes, Ledesma, Salas, Silvestre. Por otra parte, en cuatro bibliotecas están presentes Ercilla, Espinel, Orozco, Rufo, Valdivielso. A partir de aquí, una larga nómina de poetas que aparecen una sola vez - especialmente significativo es esto en las bibliotecas del conde de Gondomar (35) y Felipe IV (55)_-, pero que apenas han dejado rastro en la memoria literaria y en el construido canon de excelencia por la historia de la literatura. Pero como esto afecta a todas las áreas culturales aludiré a ello más adelante.

El hecho cierto y contundente es que el gran poeta latino Virgilio, específicamente por su Eneida, aunque aparezcan también otras obras, ocupa el primer lugar con su presencia en 21 bibliotecas con 47 ejemplares, y el también poeta latino Ovidio, el segundo (20 bibliotecas, 60 ejemplares). En consecuencia, es la poesía clásica latina, y no la española, la que ocupa la cúspide. Pero también es muy importante el que Petrarca ocupe el tercer lugar (16 bibliotecas, 41 ejemplares). Los fríos datos numéricos - aun con todas las limitaciones apuntadas y sin entrar en cuestiones específicas de lectura- muestran que la cultura clásica latina y la italiana con tres autores excepcionales construyen el canon de excelencia. Otra cosa es, como ya digo, que en él no entren hasta el puesto quinto, y con un autor del XV, los poetas españoles.

Prescindiendo de los seis poetas peninsulares en puestos $5^{\circ}, 7^{\circ}, 9^{\circ}$ y del griego Homero $\left(10^{\circ}\right)$, el resto del «escalafón» lo siguen ocupando poetas latinos e italianos, lo que me parece muy significativo y corrobora lo que venimos viendo.

Gradualmente, nos vamos apartando de esos puestos relevantes de 21 a 16 bibliotecas, pero todavía en trece bibliotecas ( $4^{\circ}$ lugar) encontramos el mundo de los emblemas de Alciato y la épica del latino Lucano. En cierto modo es coherente con esto el que el quinto lugar (12 bibliotecas) lo ocupe Ariosto, en particular con su poema caballeresco Orlando furioso, de tan importante repercusión; el séptimo (nueve bibliotecas) el también importante poeta «épico-caballeresco» Torquato Tasso, y el octavo (ocho bibliotecas), en esa misma línea, Boiardo. Sin olvidar que a la cabeza de todo está el gran épico latino Virgilio, como hemos visto. Algo puede significar, quizá, todo esto, y más si tenemos en cuenta la presencia de Homero en décimo lugar (seis bibliotecas) y la aparición en cuatro bibliotecas de autores de épica culta como Ercilla o Rufo.

En los puestos $6^{\circ}, 9^{\circ}$ y $10^{\circ}$ siguen apareciendo poetas latinos, de la talla de Horacio ( $6^{\circ}$, once bibliotecas), y otros importantes, pero de menor presencia en 
la memoria literaria, lo que ya es en sí un dato relevante, como Juvenal y Prudencio $\left(9^{\circ}\right.$, siete bibliotecas), y Marcial $\left(10^{\circ}\right.$, seis bibliotecas). Dante ocupa un octavo lugar: ocho bibliotecas, 14 ejemplares.

La importancia de la poesía latina e italiana, que venimos viendo, la corrobora también el hecho de que todavía en cuatro bibliotecas, aunque ahora la proporción sea más modesta, encontramos a poetas latinos como Ausonio, Lucrecio, Propercio, Tibulo, o italianos como Dolce, Sannazaro, Bernardo Tasso. $\mathrm{Y}$ en tres bibliotecas a Claudiano, Persio y Terracina, respectivamente.

A partir de aquí hay multitud de poetas, de las distintas áreas culturales, que aparecen sólo en una biblioteca - especialmente es importante esto en las del Conde de Gondomar y Felipe IV, como dije- Sería interminable y prolija la relación aquí caso a caso (el lector interesado puede comprobarlo en «Relación de Inventarios»). Muchos de ellos apenas han dejado rastro en la memoria literaria, lo que ya es un dato sobre las diferencias entre la realidad del siglo y la realidad construida por la historia de la literatura. Pero no deja de haber algunas diferencias significativas entre el canon de excelencia construido por la historia de la literatura y la aparición en una sola biblioteca. Aparte de los latinos (Estacio, Juvencio...) y griegos, en lo que concierne a la literatura española tenemos los significativos ejemplos (además de Quevedo, ya citado) de Acuña, Barahona, Jáuregui, López de Úbeda..., limitados a la biblioteca del conde de Gondomar. Y Villasandino, hermanos Argensola, Bocángel..., en la de Felipe IV. Naturalmente, la relación podría seguir, pero baste por ahora con esto.

Y puede que una nómina de ausencias de poetas que la memoria literaria ha consagrado añadiera elementos de juicio a lo que venimos viendo, pero no alteraría las conclusiones en lo que aquí es pertinente.

\section{RELACIÓN DE INVENTARIOS DE LAS BIBLIOTECAS}

Ya me he referido en el apartado 2 a los problemas generales de las fuentes de información (y allí remito), pero conviene ahora hacer algunas puntualizaciones concretas antes de pasar a la relación de inventarios, con los libros de poesía en cada uno de ellos.

Sólo doy autor (apellido, excepto cuando plantea dudas), título cuando no se ha identificado al autor y obra entre paréntesis cuando hay duda, y entre interrogaciones cuando puede haber más obras con ese título, utilizando, en general, las identificaciones que proponen los editores de los inventarios. No hago distinción entre lengua original y traducción, y no incluyo aquí cuando el original es en prosa. De cada autor doy el número de veces que aparece su obra en cada biblioteca, entre paréntesis. En los inventarios 35 (conde de Gondomar) y 55 (Felipe IV) sigo los epígrafes de las clasificaciones, pero sitúo en su lugar, en general, según la lengua original aunque aparezcan en otro apartado; indico 
con asterisco las dudas. Por los miles de libros que aparecen en estas dos bibliotecas, problemas de clasificación e identificación..., ha podido producirse, a pesar de las varias revisiones, alguna ausencia, duplicidad o error, que lamento, aunque no afecten al sentido y conclusiones del estudio. No tomo en consideración, en el conjunto, salmos, letanías, canciones litúrgicas, libros de música, ni cuando de un autor sólo se mencionan «obras», como en Covarrubias, Policiano, Ateneo, Orozco, etc. Excluyo, por problemas de identificación y adscripción genérica, una serie de autores y obras (indico título cuando no figura el autor): Coloma (4). Silva de varios autores; Floresta española (6). Álvarez (7). Saldaña; Camilo (8). Baptista; Tintelman; Soria; Ioachim; Virgilio sobre Antonio de Nebrija (18). Hermosilla; El Pelayo; Fábula de Adonis; Lucrecia Morena (21). Biblioteca hispánica; Picrio (25). La historia troyana; Silva nupcial (29). Ojea (30). Oviedo de Anguilano; Laçon; Olivia de Sauco; Galiçio (31). Tirses y Tirseo; Guzmán; Diálogos de amor de Dorida (34). Pasquino (36). Velázquez; Mártires; Villava; Álvarez; Vega; Historia de San Isidro; Pérez de Herrera (38). Hernández Blasco; Alexio Piamonte (41). Céspedes; Historia del rey don Rodrigo; Milagros de Nuestra Señora; Las nueve peñas (43). Padilla (45). Zamora (46). Fábula pastoril; Arte del Antonio; Discreción del teatro del cielo (48). Tragedia de Europa; Miranda; Mayante de la muerte de Orlando; Orfeo en griego; Fábulas del Pronario; Prólogo de la primera epístola de Ovidio; Pelea de Acteón y Hércules; Petrarca espiritual (51). Matheo; Villalba (54). Fiestas de Lerma (56). Poggio florentino (59). Poliantea; Sidorio Apolinar; Ortelio; Erici Puteani; Pontano; Filostrato; Mateo; Céspedes; Ateneo; Espinosa; Hermani Hugon (63). Boccalini (64).

Hay que tener muy presente todo lo que se dice en el apartado 2. Los problemas de las fuentes de información, en particular lo que concierne a títulolibro-registro. Cuando un título son varios volúmenes se cuenta como uno y cuando en un mismo volumen aparece la obra de varios poetas se computan individualmente. Pero, además, a la hora de indicar el número de libros en cada biblioteca (excepto en alguna ocasión en que no ha sido posible) hay que tener muy presente todo lo que se dice en el mencionado apartado. No recojo la bibliografía específica sobre las bibliotecas estudiadas.

\section{RELACIÓN}

1 (1602) — «Brianda de la Cerda y Sarmiento. Duquesa de Béjar», Dadson, Trevor J., Libros, lectores y lecturas, Madrid, Arco/Libros, 1998, págs. 424-431.

- 58 registros: Virgilio, Ovidio, Lucano

2 (1602) — «El gusto por la historia: la biblioteca de don Álvaro de Córdoba (...)», Prieto Bernabé, José M., Lecturas y lectores. La cultura del impreso en el Madrid del Siglo de Oro (1550-1650), Mérida, ERE, 2004, II, págs. 69-73.

- 27 registros 
3 (1602) - «Disociación entre lecturas y actividad laboral. Magno Lucenberg, agente de negocios de los Fúcares, (...)», Prieto Bernabé, José M., Lecturas, págs. 315-318.

- 24 registros: Virgilio, Ercilla

4 (1602) — «Lecturas tradicionales en la biblioteca de Pedro García Carrero, cerero (...)», Prieto Bernabé, José M., Lecturas, págs. 382-386.

- 36 registros

5 (1603) — «El platero Juan de Arfe y Villagarcía y el inventario de sus bienes», Barrio Moya, J. L., Anales del Instituto de Estudios Madrileños, 19 (1982), págs. 30-31.

-23 registros: Ovidio (2)

6 (1604) - «Dos Antonios de Segura y la librería de Antonio de Sigura», Astrana Marín, Luis, Vida ejemplar y heroica de Miguel de Cervantes (...), Madrid, Instituto Editorial Reus, 1958, VII, págs. 792-793.

- 54 registros: Lope de Vega; Garcilaso de la Vega; Ovidio (4); Alciato; Virgilio; Guajardo; B. Tasso

7 (1604) — «Alonso de Barros (1604)», Dadson, Trevor J., Libros, págs. 369-383.

- 151 registros: Petrarca (3); Pérez de Guzmán; Libro de los cuatro cantos (Fuentes); Glosa sobre las Trescientas de Juan de Mena; Silvestre; Ovidio; Virgilio; Lucano

8 (1604) — «Los libros de Bernardino de Mendoza (1540 [41]-1604)», Laspéras, Jean-Michel. Bulletin Hispanique, 99, 1997, págs. 25-39.

- $87+3$ registros: Virgilio (2); Lucano (2); Marcial (2); Obras y hazañas de Bernardo del Carpio (¿Valbuena o Alonso?); Horacio; Illustrium poetarum; Poemata Sacra; Romanceros (2); Romances nuevos (Flores); T. Tasso; Poetas griegos en latín; Caballero determinado; Aldana

9 (1605) — «Antonia de Ulloa, condesa de Salinas (1605)», Dadson, Trevor J. Libros, págs. 431-436.

- 41 registros: Romances

10 (1607) - «La biblioteca del canónigo zaragozano Pedro Arguedes» (A. Borrás Feliú, «Fundación del Colegio de la Compañía de Jesús en Huesca [1595-1625]»), Hispania Sacra, XXXII, 1980, págs. 59-87.

- No da inventario

11 (1607) - «El pintor Luis de Carvajal y el inventario de sus bienes», Barrio Moya, J. L., Boletín del Seminario de Estudios de Arte y Arqueología, 48, 1982, págs. 414-420.

$-11+25$ registros

12 (1609) - «Libros e instrumentos de música en inventarios post-mortem del Siglo de Oro español: el caso de don Juan de Borja (1607)», Dadson, Trevor J., Pliegos de Bibliofilia, 14 (2 trimestre 2001), págs. 3-18.

- 34 registros (Varios incluyen varios libros)

13 (1609) - «Libros y libreros en Murcia según los protocolos del siglo XVII», [Pedro Monte, abogado], Pascual Martínez, Lope (de), en El libro antiguo español, II, ed. M. L. López Vidriero-P. M. Cátedra, U. Salamanca - BNM -SEHL, 1992, págs. 163-175.

- 16 registros (Para varios cuerpos y uno colectivo)

14 (1609) - «Una biblioteca fuertemente secularizada: la de Alonso Carrión, platero de oro (...)», Prieto Bernabé, José M., Lecturas, págs. 375-380.

- 54 registros: Marcial; Lucano; Fuentes; Alciato (2); Virgilio; Ovidio (2); Rufo; Horacio; Flores poetarum; Micael poeta, Juvenal

15 (1609) — «La biblioteca del bordador Daniel Rutierier (...)», Prieto Bernabé, José M., Lecturas, págs. $380-382$.

- 19 registros: Covarrubias; Aníbal Caro

16 (1610) — «Francisco Arias Dávila y Bobadilla, IV conde de Puñonrostro (1610)», Dadson,

Trevor J., Libros, págs. 342-357.

- 182 registros: Ariosto; Ger[oni]mo Savorgano en italiano; Alciato; Reglas de milicia en verso y romance; Lucano; Petrarca 
17 (1611) — «Los libros de Bernardino de Villafranca, platero de oro (...)», Prieto Bernabé, José M., Lecturas, págs. 430-434.

- 43 registros

18 (1611) - «El inventario de las bibliotecas de San Juan de Ribera en 1611», Cárcel, Vicente, Analecta Sacra Tarraconensia, XXXIX, 1966, págs. 319-379.

- 1990 registros (en alguno, varios): Covarrubias; Ausias March; Homero (2); Virgilio (2); Octavianum Mirandulam; Poete cristiani; Alciato; Carmina Salmoni Marciani; Lucano; Horacio; Petrarca; Orozco; Epigramatum graecorum; Valerio Flaco; Catulo-Libulli-Propercio; Iacobi Fero

19 (1612) — «La librería de Oliverio Danes, capellán de Felipe III (1612)», Barrio Moya, J. L., Cuadernos de Bibliofilia, 14, 1987, págs. 63-68.

- 51 registros: Virgilio

20 (1613) — «La librería del arquitecto Juan Gómez de Mora» («Documentos para la biografía de Juan Gómez de Mora»), Agulló y Cobo, M., Anales del Instituto de Estudios Madrileños, 9, 1973, págs. 64-66.

- 69 registros: Virgilio; Heroni Alexandrino (4); Romancero

21 (1608, inventario; 1613 muerte) - «La biblioteca manuscrita del condestable Juan Fernández de Velasco (+1613)», Andrés, Gregorio de, Cuadernos bibliográficos, 40, 1980, págs. 5-22.

- 194 registros: Petrarca (4); Ovidio; Horacio; Carmina ad diversos; Dante (3); Versos en lengua portuguesa; Virgilio; Frebuno; Catulo-Propercio-Tibulo; Prudencio

22 (1614) - «La biblioteca del arzobispo Hernando Arias de Ugarte: bagaje intelectual de un prelado criollo (1614)», Hampe-Martínez, T., Thesaurus, 42, 1987, págs. 337-361.

- 417 registros

- Lope

23 (1616) - «Licenciado Pérez de Aracil, del Consejo del Rey» («Obras de Cervantes en bibliotecas del siglo XVII y su tasación»), Astrana Marín, Luis, Vida, pág. 794.

- No da inventario completo. Cervantes.

24 (1616) — «Ana Piñeiro Manrique, III Condesa de Puñonrostro (1589-1616)», Dadson, Trevor J., Libros., págs. 438-450.

- 126 registros (Incluye dote, 1589, e inventario, 1616)

25 (1616) — «La librería del obispo José González Díaz de Villalobos», Barrio Moya, J. L., Hispania Sacra XLIII, 87, 1991, págs. 329-341.

- c. 183 registros (varios tomos)

26 (1618) - «El arcediano de Cuenca D. Luis de Castilla (+1618) protector del Greco y su biblioteca manuscrita», Andrés, Gregorio de, Hispania Sacra, 35, 1983, págs. 87-141.

- 434 registros («quince cuerpos sin identificar, que, entre otras materias, incluyen las bellas letras» pág. 129): Mena Miscelanea poematum diversorum; Tibulo; Catulo y Propercio; Catonis et aliorum carmina moralia: Flores et sententiae (Catonis, Teognis, Aliorum)

27 (1618) — «Un regidor madrileño instruido en leyes: la biblioteca de Francisco de Peralta», Guerrero Mayllo, A., Espacio, Tiempo y Forma, Serie IV, Historia Moderna, V, 1992, págs. 71-96.

— 700 registros (1175 volúmenes) (pág. 74): Ovidio (2); Propercio; Catulo y Tibulo; Juvenal

28 (1618) - «Pedro Ocón, canónigo de Toledo», Astrana Marín, Luis, «Obras de Cervantes...», Vida, pág. 795.

- No da inventario completo

29 (1621) - «Biblioteca del protonotario Agustín de Villanueva», Saltillo, Marqués del, «Bibliotecas, libreros e impresores madrileños del siglo XVII», RABM, LIV, 1948, págs. 257-260.

- 138 registros: Virgilio (2); Ovidio; Justa poética de la Concepción; Petrarca; Juan de la Cruz; Ausonio 
30 (1621) — «Libros de Pedro de Párraga», Ibídem, págs. 261-263.

- c. 87 registros: Covarrubias; Oña; Valdivielso

31 (1621) - «Juan Bautista de Monegro, su biblioteca y 'De divina proportione'», Marías, Fernando, Boletín de la Real Academia de Bellas Artes de San Fernando, 53, 1980, págs. 91-117.

- 610 registros (pág. 92): -«6 \% libros literarios o de entretenimiento, poesía, teatro, novela, épica» (pág. 93): Horacio (2); Dante (2); T. Tasso (4); Ovidio (4); Virgilio (4); Ariosto (2); Petrarca; Mena; Celo en italiano; Cueva; Virués; Villalobos; Ausias March; Sannazaro; Estanci di diversi poeti italiani; Boiardo; Herrera; Garcilaso

32 (1622) - «Una colección con pretensiones intelectuales: la de don Fernando Pacheco, caballero de la Orden de Calatrava (...)», Prieto Bernabé, José M., Lecturas, págs. 61-68.

- 69 registros: Lope de Vega; Juan de la Cruz

33 (1622) - «Libros del marqués de Celada», Astrana Marín, Luis, «Obras de Cervantes...», Vida, pág. 795 .

- No da inventario completo

34 (1622) - «Entretenimiento y vocación intelectual a través de la lectura. Andrés Benito, mercader portugués (...)», Prieto Bernabé, José M., Lecturas, págs. 318-327.

- 89 registros: Sa de Miranda; Estaza; Bernardes; Camoens; Petrarca (2); Alciato; Ledesma; Montemayor (2); Virgilio; Íñigo de Mendoza; Espinel; Ausias March; Boiardo; Dante; Ariosto; Barros

35 (1623) - «Inventario de la librería del conde de Gondomar», Manso Porto, Carmen, Don Diego Sarmiento de Acuña, conde de Gondomar (1567-1626). Erudito, mecenas y bibliófilo, s. 1., Xunta de Galicia, MCMXCVI, págs. 415-636.

— Más de 6471 registros (pág. 417)

\section{LIBROS DE POESÍA GRIEGA:}

Homero (6); Homero y Hesíodo; *Synesii episcopi Cirensis; Teognidis, Hesíodo, Teócrito; Teognidis, Pitágoras, Focílides; Theognidis, Pytagorae, Phocilidae et caetorum carmina; Teócrito (2); Florilegium diversorum epigrammatum in septem libris; Apolonio de Rodas; Píndaro; Píndaro con Calimaco himno; Gregorio Nacianceno.

\section{LIBROS DE POESÍA LATINA}

Virgilio (13); Horacio (8); Ovidio (15); Lucano (3); Juvenal (4); *J.F. Quintiani; Alberti de Eyb; Marcial (3);Corpus omnium veterum poetarum latinorum; Juvenal y Aulio Persio; *Papini Statii; *C. Lucelio Syessani; Horacio, Juvenal y Persio; Valerio Flaco, Argonauticon libri; *Jerónimo Vidau; *Merlini Cocaii; *Joanis Felicis; *Fulvio Ursino; Horacio cum animadversionibus; *Juan Verzosa; Ausonio (3); *Silii Italici; Aulio Persio Flaco; Capiluporum carmina; Aloysii Mormillis; *Ramirus; Latini; *Sparke et Centellis; Damiani; Frischlini; *Hillessemii; Gohaei; Gellii; De nuptiis comitis Palatini cum Elisabetha Jacobi regis Angliae filia, poema; *Academia conimbricensis; Lupecii de Hoyos; *Bartolini; Barclaii; Majeri; Rollenhagii; *Sancti Orientii; Nunnii; *Garlandia; *Biffi; *Casae; Quaerengi; Prudencio (2); *Solli Sidanl(ii) Apollinaris; Pisani; *Toletani; Gemmae; Falconis; *Capyeii; *Reusneri; Carmina quinque ilustrium poetarum; *Terentii Flores; *Borbonii; *Publica laetitia sodalitatis $B$. M. Virginis; *Barclaii; *Herrerae; Vilchii; *Roscii Hortini; Claudian; Juvenalis et Persii, *Silius Italicus de secundo bello punico (2); *Drurei; *Mantuani; *Faerni; *Natalis; *Mythologici latini omnes recensuit Hieronymus Commelinus.

\section{LIBROS DE POESÍA CASTELLANA}

Romancero general (Flores); Urrea; Las quatrocientas respuestas (Escobar); *Fernández de Villegas; Mena (5); Enzina; Pérez de Herrera; Carrillo y Sotomayor; *Borja; Martínez; *Cayrasco; Hojeda; Lope de Vega (6); *Hernández Blasco; Covarrubias; Orozco; Mendoza (2); 
Cancionero general (Hernando del Castillo); López de Mendoza (2); Primera parte de las flores de poetas ilustres de España (Espinosa); *Soares; *Verdadero entretenimiento del christiano; Pelegrín; Jorge Manrique (2); Bonilla; *González de la Torre; *Gómez; *Garrido de Villena; *Zamora; *Castellanos; *Molina; *Adame de Montemayor; *Quirós; Zapata (2); Herrera; $2^{a}$ parte del Romancero general (M. de Madrigal); Montemayor (3); *Estaciones del christiano; Romero de Cepeda; Acuña; El cauallero determinado (Marche; trad. Acuña); Barahona de Soto; *Povoas; *Camargo; *Villalba; *Bravo; López de Úbeda (2); Jáuregui; Barros (2); *Sánchez Galindo; Padilla (3); Toledano; Ledesma; Espinel; *Cantoral; Salas; *Suares de Chávez; Soto; *Andrada; Archimusa de varias rimas y efectos; *Guzmán; Virués (2); *Solorzeno; *Savariego; Valbuena; *Almendáriz; Castillejo; *Contreras; *López de Corelas; Ercilla (4); Oña; Valdiuielso; Rufo; *Sancta María; Liaño; Gómez d’Oliveira; Lasso de la Vega; Romero de Cepeda; Boscán y Garcilaso de la Vega; *Hurtado de Mendoza; *Vargas Manrique; Primera parte del tesoro de divina poesía, recopilado por Esteban de Villalobos; Ausias March (2); Damián de Vega; *Segura; Historia del Cid Ruy Díez de Biuar (Recopilada por Juan de Escobar); Villegas; *Méndez de Vasconcellos; *Aguilar; *Santisteban; *Heredia; *Escobar; Suárez de Figueroa; Fuentes; Aldana; *Sans; *González del Torneo; *Alarcón; *Martínez; *Corte Real; *Mata; Bonilla; Cancionero general; Vezilla; Enzinas; *Cortés; *Soto; Cervantes; *Reyes; *Cueva; Mesa (2); *Díez; Silva de varios romances; Garcilaso; Pinciano; Saavedra Guzmán; *Dessi; Romancero historiado (L. Rodríguez); Cancionero de romances; Cueva (3); Coloma; *Gonzalez de la Torre; Medinilla; *Padilla; *Arbolanche; *Suárez de Chaves; *Ponce; Romances sacados de la Crónica d’España (Sepúlveda); López de Zárate; Piño; $1^{a}$ parte del Romancero historiado (Segura); *Girón y de Rebolledo; Castilla; *Guzmán; *Los memorables dichos y sentencias de varios philósophos y oradores; *Cosme de Aldana.

\section{LIBROS DE POESÍA PORTUGUESA}

Cancioneiro geral; Cancioneiro geral (García de Resende); Rodrígues Lobo (5); *Successo do segundo cerco de Diu; *Corte Real; Ferreira; Camões (6); Bernardez (3); Diaz; Sáa Souto Mayor; Sáa Miranda (2); Dandrada; Mousinho (2); *Alvarez de Oriente; *Lopez.

\section{LIBROS DE POESÍA ITALIANA}

*Ceba; Dante (2); Ariosto (8); *Brusantino; B. Tasso (2); Sarrocchi; *Discrittione d'alcune isole; *dell`Uva; *Le sententiose imprese et dialogo del Symeone; Mazzone; *El valeroso Bobo di Antona; *Il libro vulgare detto La Spagna; *Cesare de Solis; *Inamoramento de re Carlo; Pulci Fiorentino; *Aspramonte: tratta de lo avenimento de Orlando; M. Ludovico Dolce (3); *Tempio fabricato da diversi coltissimi ingegni; *Bobo d'Antona; *Menechini; *Inamoramento de Rinaldo de Monte Albano; *Libro 3 et ultimo dell'namoramento di Lancilotto Ginebra; *Giovio; *Scandianese; *Dragoncino; Farfarano; *Spensa; *Caputti; *Scrigni; Cacciaimici; *Fratta; *Teluccini; *Botero; Pasqualigo; *La historia de Melon e Berta; Fiamina; T. Tasso (6); Petrarca (8); *Cornazano; *Baiardo; *Ciecho da Ferrara; Pitocco; *Le rare imagini delle honorate signore napolitane; Alemanni; *Marina; Raccolta d'orationi et rime diversi; Caporal; Colonva; Terracina y Tullia di Aragona; Terracina; *L'istesso discorso con l'amorosi ragionamenti: tradotto per Ludovico Dolce d'uno anticho greco; Lionardo; Rinaldi; Tromba; *Cerboni; Nuova scelta di rime di diversi ingegni; Casa; *Gatti; *Il primo libro dello inamoramento di Messer Tristano et di Madonna Isotta; Prima parte delle stanze di diversi ilustri poeti. Raccolte da Ludovico Dolce; *Camilli; *Aquilano; Politiano; Comanini; *Antonisso; Cei Fiorentino; *Troiano; Alciato (3); Boyardo; Sannazaro; Giraldi.

\section{LIBROS DE POESÍA, COMEDIAS, Y HISTORIAS FABULOSAS}

Libro de poesías diferentes; Varias poesías en la muerte de don Felippe $2^{\circ}$; Poesías diferentes (5); Poesías de diferentes autores (5); Alvar Gómez (2); Góngora; *Libro de cantos y tonos 
diferentes; *Lope de Salinas; Poesías diferentes en romance e italiano; Penagos; Fray Luis de León; Poesías (2); *Empresas, motes y dichos que se hicieron en Nápoles en la vigilia de san Juan Baptista; *Libro de casos impensados y particularmen<te> acaescidos en Turquía; *Glossa del Pater Noster, de Silvestre; Cairasco; *Phrigio; Cetinas; Libro de poesías, llámase Arca de Noé; Poesías diferentes impressas y de mano; Libro de redondillas espirituales; *Galera armada de los inconvenientes de la vida; Los doce signos del Zodiaco; *Cabredo; *Historia del rey de Inglaterra Perséfores y Gadífer, su hermano.

VIII. LIBROS DE DE CIENCIAS Y COSAS DIFERENTES

- Pierii

IX. LIBROS DE RITRATOS

- Georgii

X. RITRATOS Y FIGURAS

- Historie et poesie raccolte da disegni di scultori et pittori

XI. LIBRO DE VARIAS CIENCIAS

- Valerian

XII. LIBROS DE MANO EN LATÍN

- Paraphasis (sic) poética in Sacram Scripturam; Liber variorum poematum; Naldii; Poemata in laudem Clementis Papae; Mampollo;

XIII. LIBROS DE MANO EN ITALIANO

- Raccolta di poesie diverse; Trayna

XIV. MEMORIA DE LOS LIBROS PROHIBIDOS

- Sátira menipea

XV. HISTORIAS FABULOSAS. ITALIANO

- Magagnati; Cornelio Gratiano

XVI. LIBROS DE CABALLERÍA Y POESÍA. FRANCÉS

- Meschinot

XVII. LIBROS DE DIFERENTES CIENCIAS Y OTRAS COSAS VARIAS

- Núñez.

36 (1626) — «Ruy Gómez de Silva, III Duque de Pastrana (1626)», Dadson, Trevor J., Libros, págs. 357-367.

- 94 registros: Tasso (3); Ariosto (2); Ovidio; Seca Rapida en italiano; Fábula rustica en poema italiano; Petrarca (2); Poemas al Papa Urbano; Poemas al cardenal Barberino; Un libro de Aquiles y Elena de Ludovico Dulze; Razonamientos de Pasquino y Marforio en lengua italiana

37 (1626) — «Francisca de Paz Jofre de Loaysa (1626)», Ibídem, págs. 453-458.

-50 registros

38 (1627) - «Los gustos literarios de una incipiente burguesía: la magnífica biblioteca de Francisco Moreno, guantero de la reina (...)», Prieto Bernabé, José M., Lecturas, págs. 387-430. 
- 399 registros: Flores de Poetas (Espinosa) (2); Pedreza (Romances); Ovidio; Virgilio (4); Guirnalda de Venus (Heredia); Otro Parnaso (¿Cervantes?); Espinel; San José en verso (¿Valdivielso?) (3); Rufo; Rimas castellanas (¿Salas Barbadillo?); España defendida (¿Suárez de Figueroa?); Mena (2); Lope de Vega; Navas de Tolosa (Mesa); Varias aplicaciones (¿Rosell?); Observancias (...) son emblemas; Homero; Maldonado; Boyardo; Petrarca (3); Ariosto; Monarquía mística jeroglíficos (¿Zamora?); Ercilla; Camoens; Orozco; Padilla (3); Dante; López de Mendoza; Lucano (2); Horacio; Traslación del Santísimo (¿Lope?); Caridazeo; Barros; El pícaro primera y segunda parte; Locos amadores.

39 (1628) - «Una persona de no modestas ambiciones intelectuales: la colección de Francisco Álvarez de Garay y Ocampo, maestro (...)», Prieto Bernabé, José M., Lecturas, págs. 269300.

- 285 registros: Virgilio (3); Ovidio (4); Marcial; Horacio; Juan de la Cruz; Alciato (comentario de Minoem); Illustrium italorum poetarum; Mena; Lope de Vega; Garcilaso (2); Juvenal; Saavedra Guzmán

40 (1629) - «Una biblioteca de alto contenido teológico: la de Fr. Íñigo de Brizuela, obispo de Segovia y presidente de Flandes de los consejos de Estado y Guerra de su majestad (...)», Prieto Bernabé, José M., Lecturas, págs. 136-145.

- 76 registros

41 (1629) — «Isabel Montero (1629)», Dadson, Trevor J., Libros, págs. 458-466.

- 94 registros: San Isidro en verso (¿Lope de Vega?); Canciones espirituales en flamenco; Silvestre; Emblemas morales en francés; Proverbios morales (¿Barros?); González de la Torre; Padilla

42 (1630) - «La biblioteca de la VI condesa de Lemos», Barbeito, Ma Isabel, en AA.VV., Varia bibliographica. Homenaje a José Simón Díaz, Kassel, Reichenberger, 1988, págs. 67-83.

- 185 registros (pág. 68): Emblemas de Boysardo en latín; Covarrubias; Ariosto (2)

43 (1630) — «La biblioteca del capitán don Jerónimo de Soto (Tradición y necesidad. La cultura de los ingenieros militares en el Siglo de Oro: la biblioteca y la galería del capitán don Jerónimo de Soto)», Laso Ballesteros, Ángel, Cuadernos de Historia Moderna, 12, 1991, págs. 83-109.

- 124 registros: Un libro de sonetos; Ovidio; Virgilio; Garcilaso

44 (1630) — «Diego de Silva y Mendoza, conde de Salinas (1630)», Dadson, Trevor J., Libros, págs. 391-409.

- 156 + 54 registros: Camoens; Rodrígues Lobo; Figueroa; Garcilaso; Homero; Mena; Sannazaro; Terracina; Osias March (¿Ausias March?); Proverbios de don Jorge Manrique (Coplas con Proverbios de Santillana); Poetas ilustres (Espinosa); T. Tasso; Barros; Versos manuscritos; [Otro] libro de poesía escrito de mano; Padilla

45 (1630) - «Juan Francisco de Tornamira y Soto (1620-1630)», Dadson, Trevor J., Libros, págs. 383-391.

$-3+23+64$ registros: Murillo (2); Petrarca; Marcial

46 (1631) - «Ficción, historia y devoción: el entorno cultural de un modesto cordonero. Manuel de Ayllón (...)», Prieto Bernabé, José M., Lecturas, págs. 448-451.

- 34 registros: Ledesma; Patriarca San José (¿Valdivielso?); Ovidio; Dolce

47 (1631) — «La biblioteca de Miguel López de Olivares, agente de negocios (...)», Prieto Bernabé, José M., Lecturas, págs. 345-346.

- 14 registros

48 (1632) - «Los libros y otros bienes de don Pedro Zorrilla de Velasco (1632)», Barrio Moya, J. L., Cuadernos de Bibliofilia, 13, 1985, págs. 29-33.

- 38 registros: Ariosto; Tasso; Ovidio 
49 (1632) — «Juan Fernández de Madrigal, secretario de su Majestad. Una colección con recursos (...)», Prieto Bernabé, José M., Lecturas, págs. 164-170.

- 38 registros: Bernardo del Carpio (¿Valbuena o Alonso?)

50 (1633) — «Sebastián de Mesa, comisario del Santo Oficio», Astrana Marín, Luis, «Obras de Cervantes...», Vida, pág. 795 .

- No da inventario completo

51 (1633) - «La biblioteca del conde de Benavente», Herrero, Miguel, Bibliografía Hispánica, XXXVII, 1942, págs. 18-33.

— c. 400 registros: Horacio; Boiardo (2); Ovidio (3); Petrarca (6); Apiano; Lucano; B. Tasso; L. Martelo; Virgilio (2); Homero; Sonetos y canciones diferentes; Ariosto (2); Mena; Ribaldio; Claudiano; Lucrecio; Juvenal; Ausonio; Prudencio; García de Resende

52 (1635) - «Una sólida preparación piadosa: los libros de Francisco López, presbítero, rector del hospital real de la Pasión (...)», Prieto Bernabé, José M., Lecturas, págs. 127-135.

- 78 registros: Catón poeta; Prudencio; Catón cum commento

53 (1636) - «El inquisidor Alonso de Salazar y Frías: el inventario de sus bienes», Barrio Moya, J. L., Boletín de la Real Academia de la Historia, 170, 1987, págs. 139-172.

- 814 registros, 1161 volúmenes (pág. 150): Petrarca; Alciato (3)

54 (1636) - «Consumo de literatura castellana de ficción: la biblioteca de don Cristóbal González Cossío de la Hoz, contador de resultas de su majestad (...)», Prieto Bernabé, José M., Lecturas, págs. 209-216.

- 62 registros: Pérez de Montalbán; Quevedo (Obras); Mena

55 (1637) - El libro y el cetro. La biblioteca de Felipe IV en la Torre Alta del Alcázar de Madrid, Bouza, Fernando, Salamanca, Instituto de Historia del Libro y de la Lectura, 2005, págs. 169 y ss.

— «2150 (cuerpos) para 1950 entradas)» (pág. 48):

\section{POETAS GRIEGOS TRADUCIDOS}

- Museo; Anacreonte; Homero (5)

\section{POETAS LATINOS TRADUCIDOS}

— Ovidio (9); Virgilio (3); Persio (2); Lucano; Horacio (2); Parnaso Antártico de Pedro Mesía (Ovidio); Robo de Proserpina de Faria (Claudiano); Juvenal; Lucrecio; *Estacio Radi;

\section{POETAS ESPAÑOLES [Y PORTUGUESES]}

- Varios poetas; Cancionero general (Hernando del Castillo); Mena (3); Garcilaso de la Vega (3); Villegas (2); Poetas ilustres de España (Espinosa); Santisteban; Castillejo; Manrique; Ausias March (2); Boscán y Garcilaso; Las cuatrocientas del Almirante (Escobar); Encina; Castelblanco (2); Aldana; El Cavallero determinado (Marche, trad. Acuña y Urrea (2); Sa de Miranda (2); Fray Luis de León y Francisco de la Torre; *Gigantomaquia (Gallego); Ercilla; Góngora (2); Rufo; Silvestre; Lope de Vega (16); Villamediana; Lupercio y Bartolomé Leonardo de Argensola; Esquilache; Rodrígues Lobo (3); La Carolea (Sempere); Salcedo; Virués (2); Bocángel (2); Romancero (Padilla); Salas Barbadillo (2); *La reina Matilde; Espinel; Égloga amorosa; Pantaleón; Íñigo de Mendoza (3); Diferentes poesías; Lizón; Lisboa edificada; Fiestas a la beatificación de Santa Teresa (San José); Tropezón de la risa (Alonso de Maluenda); *Glosa al Marqués de Santillana; Tesoro de varias poesías (Padi1la); *Manuel de Portugal; Figueroa; *Glosas al Marqués de Santillana y Juan de Mena; *Zamora (2); Mosquera; Zapata; Ferreira; Bernardes (2); *Alabanza de los ingenios sevillanos; Endimión (Díaz Callecerrada); Romancero general; *España libertada; Batalla de Roncesvalles (Espinosa); Elogios al Retiro; Camoens (2); Carrillo. 


\section{POETAS ITALIANOS Y FRANCESES}

- Dante (2); Ariosto (2), T. Tasso (9); Baldo; B. Tasso; Colona (2); Boyardo; Marino (4); *Alemani; Jardín de rimas; Dolce (2); Petrarca (5); Ronsard; Olenix; Du Bartas (3); Dono; Rimas de diversos a la Señora Livia Colonna; Marquesa de Pescara; Tansillo; Flores de las rimas de los poetas ilustres de Italia (Ruscelli); *Apología contra Castelvetro; *Sátiras de diversos autores; *Camilo; Caporal; Terracina; Stiliano; *Trisino; Versos en alabanza del Escorial (Strassoldo); Rimas de diversos (col. Dolce); Goselino; *El enamoramiento de Reinaldo; *Primeros estudios de Gabriel Simón; Poesías vulgares (Medici); Paternó (2); Talenti; Caporal y otros; Estancias de diversos autores toscanos; Nuncio Legato (González de la Torre); Exequias poéticas; *Apólogos del Capacho (Aníbal); *Fuente del Deleite; Aquilano; *Castaleti; *Elogios a la duquesa de Briciano; *Arminia (Visconti); Rimas espirituales; Aníbal Caro y otros; Rimas de Aníbal Caro y del Marteli; Sannazaro; Chiabrera; Gonzaga; Folenga.

V. MÚSICA

- Marencio

VI. MEMORIA DE LOS LIBROS QUE ESTABAN EN EL BUFETE

- Soto de Rojas

VII. FILOSOFÍA NATURAL Y MORAL Y RACIONAL

- Targa; Fábulas del Pavesi; Barros

VIII. LIBROS VARIOS DE DIVERSAS LENGUAS

- Alciato; Benamati; Covarrubias (2); Yagüe; Gonzaga; Cinquanta; Vida-Belli; *Ruscelli; *Boccalini; *De los Reyes

56 (1637) - «Libros para el buen cristiano: el ejemplo de la biblioteca de doña Francisca de Padilla, marquesa de Auñón (...)», Prieto Bernabé, José M.a ${ }^{a}$ Lecturas, págs. 485-488.

- 29 registros: Excelencias de Nuestra Señora (¿Padilla?); Libro de San José (¿Valdivielso?); Fiesta de Lerma (Lope de Vega)

57 (1638) — «La valiosa colección de Códices del Conde de Guimerá en la Biblioteca Nacional», Andrés, Gregorio de, en AA.VV., Varia bibliográphica, págs. 47-54.

- 67 registros: Dante; Ausias March; Cancionero portugués; Murillo

58 (1638) — «La librería y otros bienes de la duquesa de Sessa (1638)», Barrio Moya, J. L., Cuadernos de Bibliofilia, 12, 1984, págs. 41-51.

- 99 registros

59 (1640) - «La librería de don Pedro Testay, capellán de Felipe IV y chantre de la catedral de Palermo (1640)», Barrio Moya, J. L., Hispania Sacra, 40, 1988, págs. 389-400.

- 303 títulos, 682 tomos (pág. 391): Lucano; Alciato (2); Ariosto; Flor de poesía

60 (1644) - «Leer historia para vivir: los entretenimientos literarios de doña Lucía de Toledo (...)», Prieto Bernabé, José M. a, Lecturas, págs. 493-496.

- 18 registros: Mena; Petrarca; Virgilio

61 (1644) - «Juan de Aguilar, caballero de Santiago», Astrana Marín, Luis, «Obras de Cervantes...», Vida, pág. 795.

- No da inventario completo

62 (1645) - «La biblioteca de Batres», F Pérez de Guzmán, Generaciones y semblanzas, ed. de R. B. Tate, London, Tamesis, 1965, págs. 99-101.

- 29 registros: Lucano 
63 (1647) - «Libros y lecturas de Rodrigo Caro», Etienvre, Jean-Pierre, Cuadernos Bibliográficos, 38, 1971, págs. 31-106.

- 530 registros (pág. 36) (Hay repetidos): Poetae Graeci Veteres; Marcial; Lucano (2); Horacio (2); Virgilio; Epigramata vetera; Ovidio (3); Poetae varii; Carmina videmani: (Bidermann); Mena; Juvencio; Alciato; Carmina illustrium poetarum italorum; Opusculum musei; Carminarum de 9 poetas; Covarrubias; Góngora; Lucano; Píndaro; Teócrito; Catulo; Ausonio (2); Juvenal (2); Lucrecio (2); Estacio; Prudencio (3); Epigramata greca (J. Soter); Spagnoli; Persio (2); Policiano; Capilupi carmina; Tibulo; Herrera

64 (1650) — «Una colección de amplios horizontes y formación humanística: la de Bartolomé de Arnolfo, mercader de ganado (...)», Prieto Bernabé, José M.. ${ }^{a}$, Lecturas, págs. 328-345.

- 153 registros: Dante (2); Grillo; Ovidio; Ariosto; Vida de Santa Teresa en verso; Boiardo; Rimas de diferentes autores; Caporal; B. Tasso; T. Tasso; Estancias de diversos poetas recogidos por Ludovico Dolca; Petrarca; Rimas de diversos autores (italiano); Julio César Cabeo

65 (1650) — «Almoneda de los bienes de Doña María Barreneche (...)», Weruaga, Ángel, $\mathrm{Li}$ bros y lecturas en Salamanca. Del Barroco a la Ilustración, Salamanca, Junta de Castilla y León, 1993, pág. 213.

- No da inventario completo: 14 registros y más: Parnaso español 